Original Research Paper

\title{
Parameter Settings for an Automated Gantry-Robot Painting System using a 3-Gun Atomization Spray Method for an Anti- Static Coating Process
}

\author{
${ }^{1}$ Zunaidi Ibrahim, ${ }^{2}$ Rozman A. Rahim, ${ }^{3}$ Shahrizal Ariffadillah, ${ }^{4}$ Zuradman Mohd Razlan, \\ ${ }^{4}$ Shahriman Abu Bakar, ${ }^{4}$ Wan Khairunizam and ${ }^{4}$ Rudzuan M. Nor \\ ${ }^{1}$ Faculty of Technology, University of Sunderland, St Peter's Campus, Sunderland, SR6 ODD, UK \\ ${ }^{2}$ Engineering Division, NS Aries Malaysia, Sdn. Bhd., Malaysia \\ ${ }^{3}$ Engineering and Operations Director Aerospace Composites Malaysia (ACM), Malaysia \\ ${ }^{4}$ School of Mechatronic Engineering, Universiti Malaysia Perlis, Arau, Perlis, Malaysia
}

\author{
Article history \\ Received: 27-09-2019 \\ Revised: 16-11-2019 \\ Accepted: 22-11-2019 \\ Corresponding Author: \\ Zunaidi Ibrahim \\ Faculty of Technology, \\ University of Sunderland, St \\ Peter's Campus, Sunderland, \\ SR6 0DD, UK \\ Email: zunaidi.ibrahim@sunderland.ac.uk
}

\begin{abstract}
Dry film thickness and appearance are the main quality improvements that can be achieved by an automated painting system in the manufacturing process. This study presents the spray coating process for aircraft parts using a gantry robot with an automated spray-painting gun to control the spray path, thus achieving the desired coating layer thickness. The experimental results show that the 3-gun atomization spray method, with high capacity airflow and outstanding atomization characteristics, poses the challenge of achieving an even thickness of the overlapping spray pattern from three separate guns, minimizing the paint material consumption and controlling the dry film thickness within the given specification and standard. The optimization was performed to control the spray path and material consumption with a 3-gun spray method to achieve the optimum setting for the spray nozzle to workpiece height to obtain the target thickness. The results show that replacing the manual process with the automated painting process can increase the speed by up to $30-40 \%$, reduce the setup time and increase the capacity of the painting booth. The development of this system can achieve the desired thickness specification, increase productivity and provide safer, more effective and ergonomic working conditions.
\end{abstract}

Keywords: Robotics, Automation, Spray-Painting Robot, Coating, Dry Film Thickness

\section{Introduction}

Aviation coatings, known as aircraft coatings or paintings, are broadly used in both commercial and military aviation industries ranging from military aircraft sector to the space sector and other flying vehicles. The aerospace sector is one of the most demanding sectors for the coatings process. The coating process which uses materials has to ensure protection from corrosion, abrasion, erosion and more within the temperature changing environments and extreme weather conditions, (Coating.co.uk, n.d.).

Smooth and uninterrupted airflow over a plane's wing is vitally important for the efficiency of flight. Leading-edge erosion is a problem also experienced by wind turbines where the front edge of a wing or blade erodes due to constant impact with rain, dirt, bugs and others. By the time, when an aircraft wing arrives at the manufacturing assembly line, similar to all other aircraft wing panels will be covered in a green protective coating. When the protective coating is removed, the paint is applied and then the aircraft wings are likewise coated with a weather-resistant coating system. The walkways on aircraft wings are also coated, this time with a non-slip coating for cargo floor panels and escape routes and payload floorboards which suggested in aerospace coatings by AkzolNobel's Aviox paint and coating standard, (Aerospace Coatings, n.d.; Mike, 2012).

Aircraft material supposed to be light and highly versatile and flexible, resistant to corrosion and fluids and provide long term endurance with gleam and gloss color retention over long life service intervals and 
maintenance. Composites are once in a while totally smooth, so the paint system needs to oblige the paint pinholes issue and voids should be filled to prevent moisture penetration. Pinholes are gaps littler than $0.5 \mathrm{~mm}$ in diameter that happen in the composite surface and can't be filled using a spraying process. The sprayed coating will bridge the pinhole and the extension will break, either by gassing out from the pinhole, by shrinking back as the coating dries or by sanding process techniques (United States Department of Transportation and Federal (Aviation Administration, 2012; Techniques, 2018).

Pinhole filling is achieved by pushing the filler into the holes using a special tool such as a squeegee. A low viscosity filler is preferred, as this can be wiped off the composite surface leaving filler in the pinhole and reduce process time and weight. The filler must be wiped in multiple directions and uniform to ensure that angled pinholes are filled properly.

Spray-painting processes have been widely used in painting and coating applications, where the paint or coating liquid is atomized and dispersed to deposit on the target surface of a workpiece. The workpiece is a panel to be painted. The spray coverage and thickness of the coating layer are the major concerns in the process. Spray guns are available in gravity feed, pressure and suction formats and a wide-ranging of conventional technology air caps come up with exceptional atomization for coating metal, ceramic, plastic, wood and composite substrates with nearly all types of solvent such as waterborne, high solids and $2 \mathrm{~K}$ materials which suggested in (Spray and Range, n.d.).

In this study, the workpiece is a composite part used in the manufacture of airplane wings. From the manual spraying process, the gantry-type automation system is developed to counter inconsistency in painting thickness, increase productivity and reduce environmental and health issues for the operators. This Automated SprayPainting System (ASPS) consists of three spray guns located on a three-axis gantry-type carrier and moves in the $\mathrm{X}, \mathrm{Y}$ and $\mathrm{Z}$ directions powered by three electrical motors. ASPS will properly control the spraying path, to achieve uniformity of the coating layer thickness (Sheng et al., 2005; Luangkularb et al., 2014). The spray gun is a type of Low Volume Medium Pressure (LVMP) by De VILBISS (Spray and Range, n.d.). This spray gun with highly and powerful airflow and impressive performance of atomization characteristics are integrated with a separate "balanced" air valve to supply an unlimited flow of compressed air through the gun body; this, coupled with light, feel-right comfort, is to produce high-quality spray coating conditions. Compared to conventional guns and High- Volume Low Pressure (HVLP) guns, the LVMP gun achieves finer atomization and higher transfer efficiency with significantly less air consumption. The DeVilbiss
Advance High Demand (HD) spray guns are ideal for small scale working operations or high-volume spraying, with the advantage of immediately improved finishing productivity. Solution mixtures supplied to the spray gun are transferred by a pressurized tank to ensure a constant supply. A separate pressurized tank is filled with thinner for flushing out balance paint solution from the transfer tube. Similarly, spray path planning and distribution pattern models are presented in (Taejung and Sarma, 2003; Somboonwiwat and Prombanpong, 2017). Li et al. (2010) presented an automatic path and trajectory planning for robotic spray painting using a CAD based method.

This ASPS system is designed for Aerospace Composites Malaysia (ACM) (ACM Malaysia, 2002) located in Kedah, Malaysia. ACM, a supplier of composite products and subassemblies to the global aerospace industry, is a strategic alliance between U.S. joint venture partners Hexcel and Boeing (Hexcel HexAMTM, 2019). The company made the difference to improve the color and gloss durability of the topcoat paint and to fulfill new regulations that mandated the use of primers and topcoats with low Volatile Organic Compound (VOC) content (Rebecca Horner, n.d.). These regulations and standards also required Boeing to make use of new and less aggressive cleaning solvents before applying paint. Using new solvents, paints and application processes produced several challenges in preparing the surface, painting and achieving a finished appearance satisfactory to the operators.

The development of ASPS started in December 2017 in our laboratory and was successfully installed and tested at Paint Booth No. 1 ACM (ACM Malaysia, 2002) in August 2018.

This paper is organized as follows: Section 2 encompasses a material and methods of the related researches of manual and automated spray painting and presents the design of the system and comparison between manual and gantry-robot use in the development of the 3-gun spray method. Section 3 describes the detail of the experimental setup. Section 4 describes the results for parameter settings and thickness requirements after implementing the proposed method. Section 5 expresses the conclusion of the proposed developed system.

\section{Materials and Methods}

\section{Literature Review}

The coatings systems used for aircraft exteriors include primers, intermediate coats and topcoats. These coatings are spray-applied in very thin layers, ensuring an even and perfectly cured application. Several paint processes, from primer to anti-static topcoat, are applied to the aircraft parts, such as wings, spoiler, flaps and ailerons, as shown in Fig. 1. Several studies have been undertaken in the analysis of spraying path, spray overlap, spray gun 
orientations and spray flow rate (Luangkularb et al., 2014; Taejung and Sarma, 2003; From et al., 2011). Regarding the reduction of downtime and an increase in productivity and efficiency, ASPS systems have been introduced. They allow the painting process speed to be increased by up to $30 \%-40 \%$ by replacing the manual process, eliminate long setup times before painting and increase the number of painting carts inside the painting booth. These ASPS systems also reduce the number of chemical strippers required, thus effecting a cost-saving. Components of an aircraft: wings, spoiler, flaps and ailerons, are painted in a paint booth at ACM. The paint booth must have temperature and humidity control, to be able to protect the components from the elements.

The quality of spray thickness and evenness of the coating layer are the major issues in the coating process with the application of the ASPS. Previously, several studies were undertaken in the analysis of trajectory and spraying path control planning for unknown 3D surfaces for industry painting robots, modelling for trajectory planning on automotive surfaces and optimization of robotic spray-painting process parameters as reported by (Li et al., 2010; Meng, 2008; Conner et al., 2005; Chidhambara et al., 2018). Controlling the spraying path is an important parameter to achieve uniformity, or evenness, of the coating layer thickness (Meng, 2008; Chen and Zhao, 2013). Real-time simulation and CADguided tool planning contributed extensively to the uniformity of spray pattern distribution and thickness deposition (Conner et al., 2005) and Analysis of a 6Degree Of Freedom (DOF) Robot Spray Coating Manipulator (Madhuraghava et al., 2018). In addition, (Tang and Chen, 2015) presented surface modeling of a workpiece and tool trajectory planning for spray painting. In our previous paper (Rudzuan et al., 2019) presented a method for the development of an automated spray-painting system for the coating process.

The conventional coating is performed by experienced operators. The anti-static coating is sprayed using a manual gravity feed spray gun inside a paint booth. Meanwhile, space for operators to maneuver in the paint booth limits the area available for the paint carts. Therefore, the number of workpieces inside the paint booth cannot be maximized. With this size of the paint booth, only six carts can be positioned inside the booth at one time, Fig. 2 .

Figure 2 shows the manual process flow as follows:

Step 1: The operator pushes 4 carts with a workpiece into the painting booth (total time took $3 \mathrm{~min}$ )

Step 2: The operator manually sprays each workpiece from carts 1 to 4, individually (total time taken $10 \mathrm{~min}$ )

Step 3: After completion of 4 carts, the operator moves these 4 carts to the edge of the painting area for the flash-off period (total time taken $2 \mathrm{~min}$ )
Step 4: The operator pushes another 2 carts with workpieces for painting (time took $2 \mathrm{~min}$ )

Step 5: Flash-off period (time took $15 \mathrm{~min}$ )

Step 6: After completion of the flash-off period for all 6 carts, the operator pushes all carts into the Warm Room for the next process (time took $3 \mathrm{~min}$ )

Process cycle time: Time is taken to complete the coating process for all 6 carts, including handling time: $35 \mathrm{~min}$.

With the elimination of these manual processes, ACM will increase their productivity and safety and improve quality, focusing, in particular, on paint thickness and color unevenness during the process. Manual painting is performed using a single gravity feed spray gun held by the operator, as shown in Fig. 3 and relies on their individual experience and expertise to spray the workpiece. The paint booth operators are exposed to high risk from chemicals as nearly every chemical used in the operation is flammable and noxious. Debris and dust can ruin the paint quality, but it can also harm the operator's lungs. Inside a paint booth, high temperatures combined with dust, debris and moisture can cause numerous lung diseases. Spraying hazards including shock can be created by clogged spray guns and filtration systems. Storage of empty cans inside a spray booth can be sufficient enough to create static electricity when adjacent to highpressure sprayers this can generate an electrocution hazard. Operators need to wear Personal Protective Equipment (PPE) shown in Fig. 3 and masks during this painting process for their safety as suggested in guidelines published for Aviation Standard (United States Department of Transportation and Federal Aviation Administration, 2012).

Flash-off time is the necessary waiting time in the Warm Room for the heating process after a coat has been applied to a component. If the flash-off time is short, irregularities such as uneven thickness can be expected. With the implementation of ASPS, productivity and effectiveness are expected to be improved as the cycle time is reduced from $35 \mathrm{~min}$ to $26 \mathrm{~min} 36$ 2nds per production cycle.

Increased and consistent product quality is the most important advantage gained by automated systems of all types. For painting or coating, film thickness tolerance and visual appearance are the most prevalent points to tackle. An industry-standard assumption is that a paint saving of $15 \%$ to $30 \%$ can be achieved by reducing overspraying when manual painters are replaced by automated systems. Automated systems are flexible to change, expansion and adaption for different workpiece sizes or paint thicknesses. Savings are achieved through film thickness tolerance control; trigger accuracy will also be directly related to many other savings. 

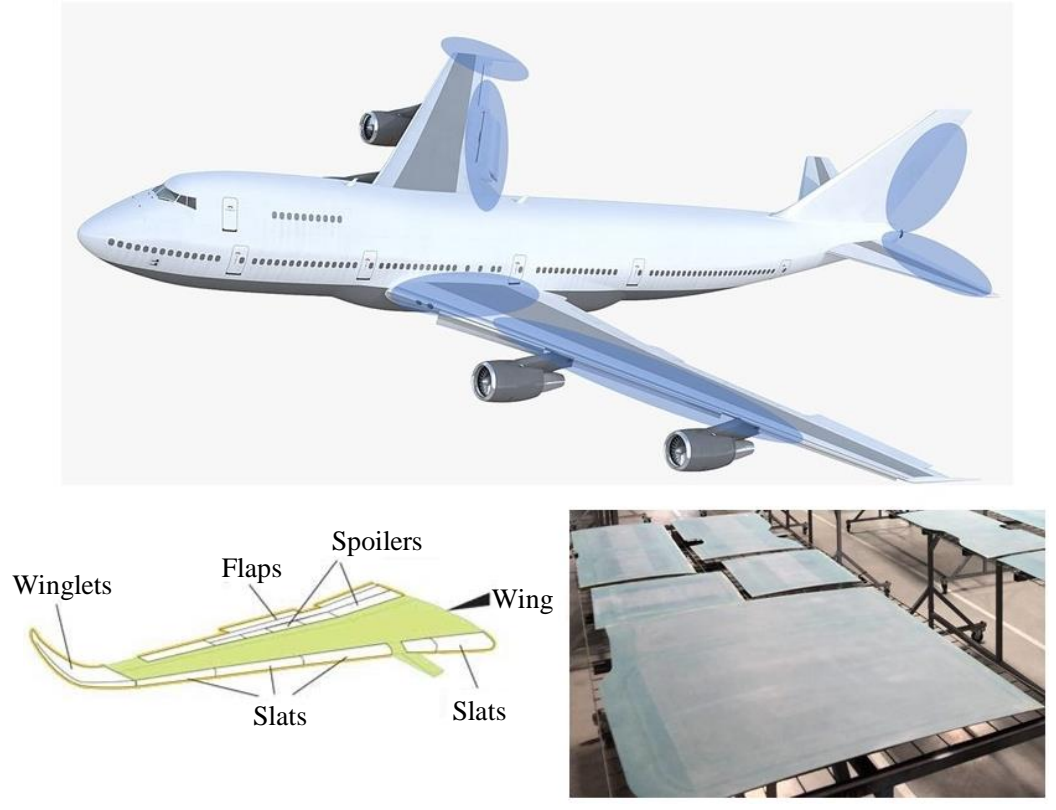

Fig. 1: Components of flight wings for coating, picture from ACM parts on a Boeing Commercial Aircraft, (ACM Malaysia, 2002)
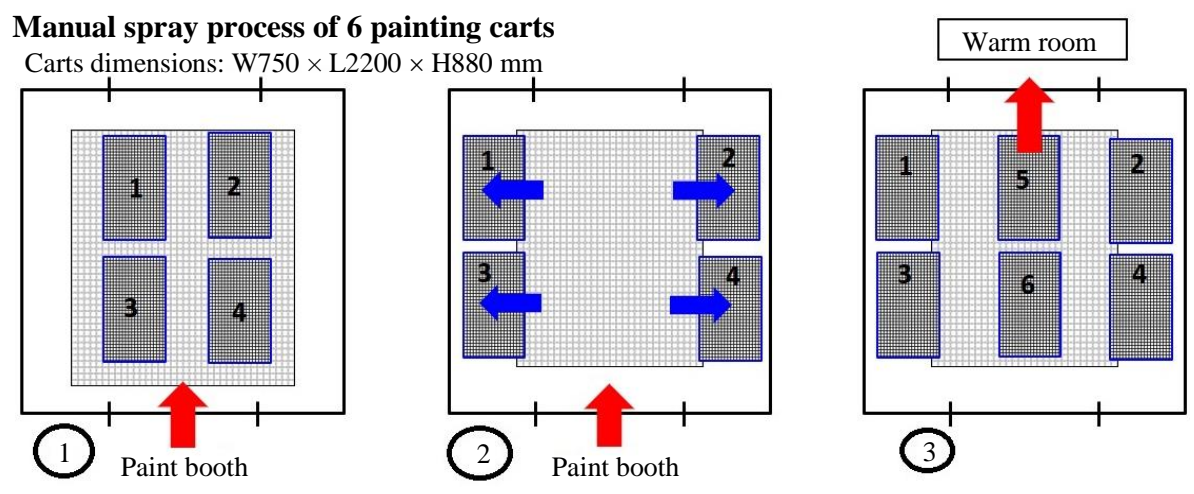

Fig. 2: Layout for manual spray process flow in conventional coating booth
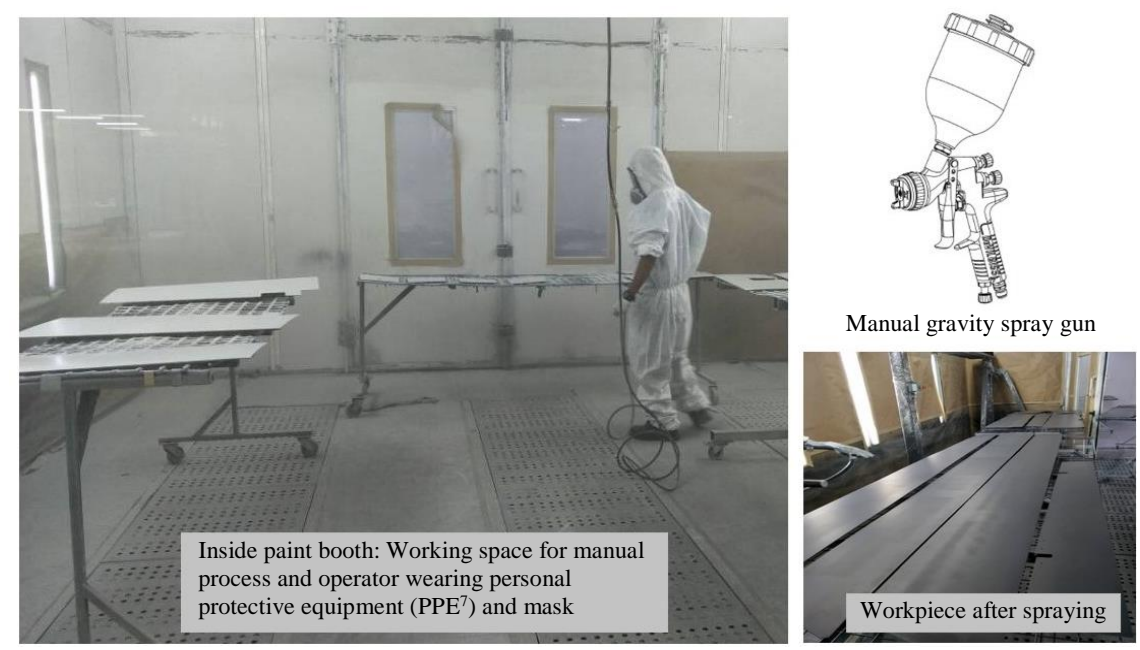

Fig. 3: Inside paint booth and manual gravity spray gun 


\section{Design and Development of ASPS with 3-Gun Atomization Spray Method}

In our previous research, we have design and develop an intelligent system related to autonomous robotic application such as the design and development of an intelligent prosthesis (Ibrahim et al., 2008), path planning based on geographical features information for an autonomous mobile robot (Zunaidi et al., 2006), complex background subtraction for biometric identification (Khalifa et al., 2007), fuzzy multi-layer SVM classification (Hariraj et al., 2018) and also fuzzy wheel controller design (Halin et al., 2018; Mustafa et al., 2018). In this research, we will evaluate and optimize the best parameter settings for ASPS and using the above research finding to develop an intelligent autonomous height control system for ASPS in the future. This research design and develop the ASPS with a 3-Gun atomization spray system using the Gantry-robot system.

Gantry-robot systems offer the advantage of large work areas and better positioning accuracy. Positioning accuracy is the ability of the robot to place a part correctly. Gantry robots are easier to program, with respect to motion, because they work with an $\mathrm{X}, \mathrm{Y}, \mathrm{Z}$ coordinate system as shown in Fig. 4. Popular applications for this type of robot are the Computer Numerical Control (CNC) machine and 3D printing. The simplest application is used in milling and drawing machines where a pen or router translates across an X-Y plane while a tool is raised and lowered onto a surface to create a precise design. Pick and place machines and plotters are also based on the principle of the Cartesian coordinate robot (Rudzuan et al., 2019; Engineering, 2015). Controlled by Programmable Logic Controller (PLC), this ASPS provides all necessary data for managing the process optimally, including nozzle selection, workpiece height control, pressure control, paint volume, XYZ spray direction and positioning and alarm buzzer, among others.

Technically, the system consists of a gantry spray gunsee Fig. 5, with movement by an explosion-proof servomotor and an adjustable spraying distance from nozzle to workpiece. To fit within the booth dimensions, the gantry system type of robot is designed with a length of $6950 \mathrm{~mm}$, a width of $4800 \mathrm{~mm}$ and a height of 2380 $\mathrm{mm}$ and is built from mild steel tube, 3 " $\times 2$ " square. The guns can move freely along the $\mathrm{X}$ - and $\mathrm{Y}$-axes supported by cable chain covered by flexible bellows and powered by a set of AC servomotors. For gun height adjustment, the gun can also move up and down, controlled by another servomotor. All servomotor movement is controlled by a PLC equipped with a touchscreen panel for automation mode and teach pendant for manual control mode.

Three AC servomotors are used in this developmentHG-SR52, HG-SR102 and HG-KR23B, all from Mitsubishi Electric Co. (Manual, 2012). Each of the servomotors is installed for controlling the spray gun mechanism in the X-, Y- and Z-axis, respectively.

The selection of the servomotor was explained in detail in a previous study on the development of ASPS mechanical design properties that included the servomotor selection and parameter settings such as load and gear type, among others and based on this actual application (Rudzuan et al., 2019).

The overall proposed system shown in Fig. 5 comprises the following items:

- Main structure with servomotor and spray gun layout

- Automated Spray Gun (Nozzle) c/w pressure tank, flow counter, tubing, etc

- Explosion-proof motor for XY control c/w cable

- Detail section for servomotor mounting

\section{Spraying Paint Booth}

Dimensions of the paint booth are $7000 \mathrm{~mm} \times 5500$ $\mathrm{mm}$ with an access door at the front, blower on the roof and vacuum mechanism on the floor, as shown in Fig. 6. There is an exit door to the Warm Room at the rear of the booth. Painted workpieces are transferred to the Warm Room for 45 min after 15 min of flashing off time inside the paint booth. The flashing-off process is a partial evaporation process or settle-down process when the liquid changes its phase and becomes partly vapor and partly liquid.

There are two pressure tanks required in the development of this system. One pressure tank is filled with the paint mixture and the other is used for solvent or thinners for flushing or cleaning purposes; use of the second pressure tank reduces the flushing or cleaning time. After the spraying process is complete, the pressure tank with the solvent is connected to the hose for the flushing process. With this versatile PT-10M pressure tank (Pressure and Temperature, n.d.), Almost professional painting results can be achieved. Special materials such as enamel paint, chemical liquids and solvent-based coatings can be delivered as smoothly as required (DeSoto ${ }^{\circledR}$ PPG Aerospace, n.d.).

Figure 6 above, shows the structural design for the ASPS. The spray gun is held by a linear guide and controlled by a servo motor for height adjustment. Another servomotor is used to move and control the ASPS axis on the linear guide. The proposed ASPS has a main control panel unit with a teaching pendant, touchscreen unit, push-button and tower light.

\section{3-Gun Spray Method}

The proposed ASPS utilizes an LVMP gun to achieve finer atomization and higher transfer efficiency. The LVMP gun with high transfer efficiency that provides superior cost performance is the DA-300 type DeVilbiss, shown in Fig. 7. 
It is used in this development because it is a compact, high-performance, general-purpose automatic spray gun with superior fine atomization and transfer efficiency. Featuring superior atomization, the gun is designed to be suitable for spraying metallic and pearltype paints. The superior atomization is made possible by using the DeVilbiss air cap that is already highly regarded in the market. Compared to conventional guns and HVLP guns, the LVMP gun achieves finer atomization and higher transfer efficiency with significantly less air consumption. These main characteristics are highlighted in the manufacturer's manual on their website (Spray and Range, n.d.).

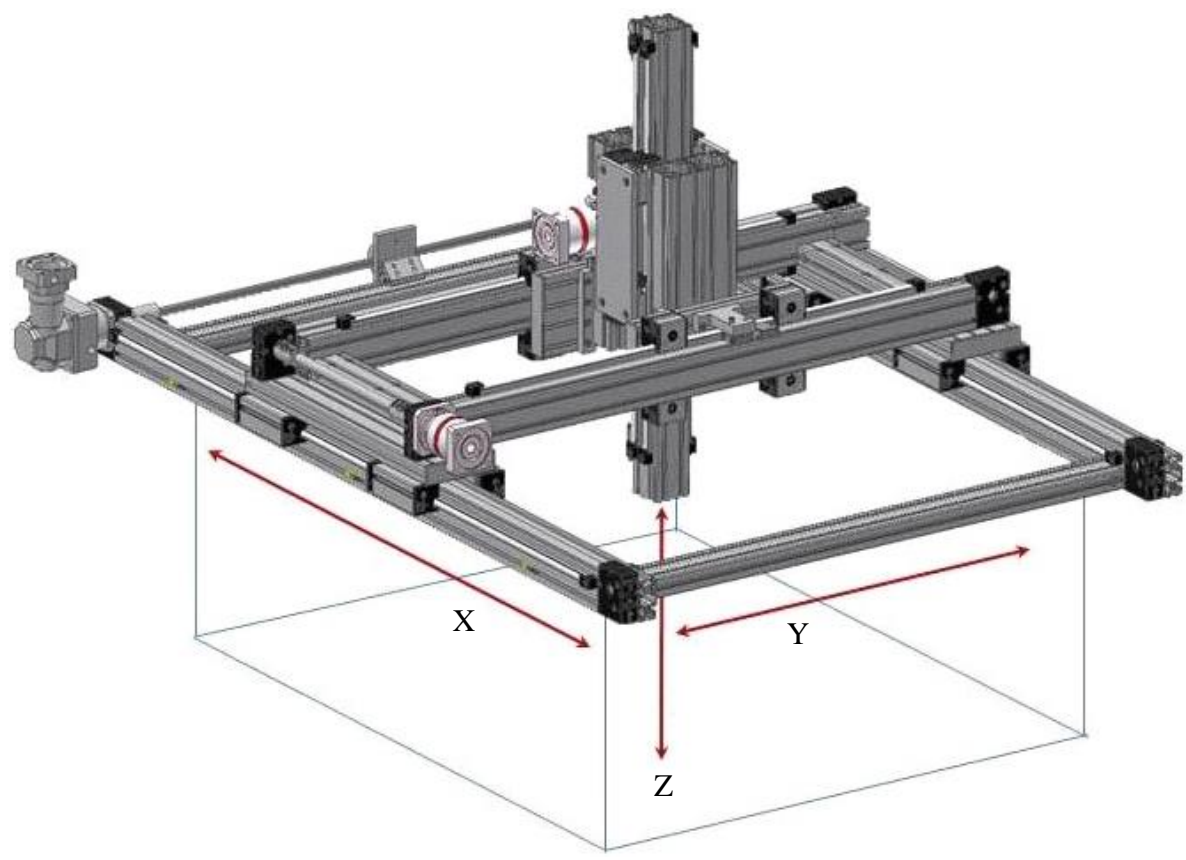

Fig. 4: XYZ Gantry-type robot-Cartesian Robot System, (Gantry Systems: Working Outside the Envelope-Macron Dynamics, n. d.)

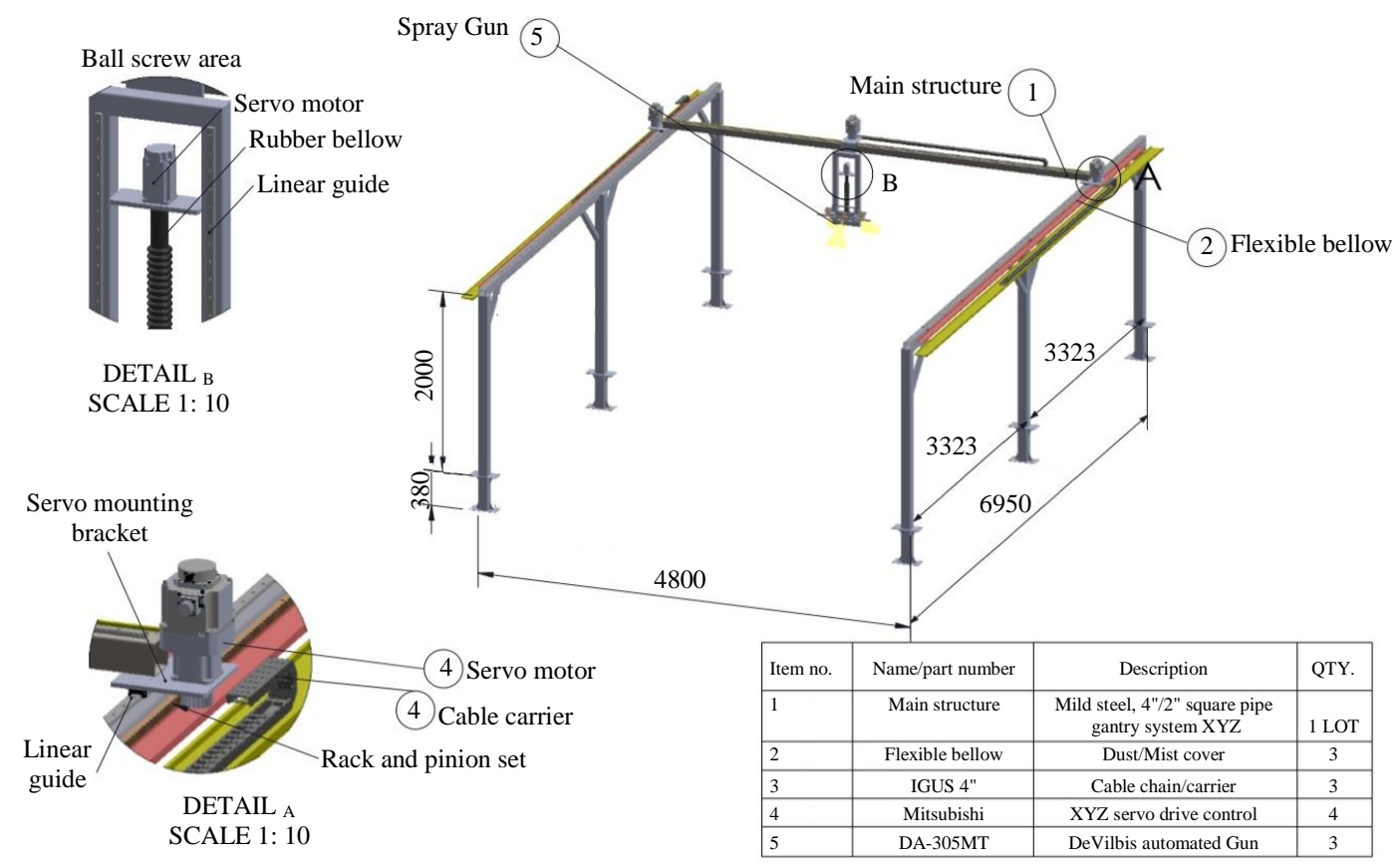

Fig. 5: The overall proposed system layout 


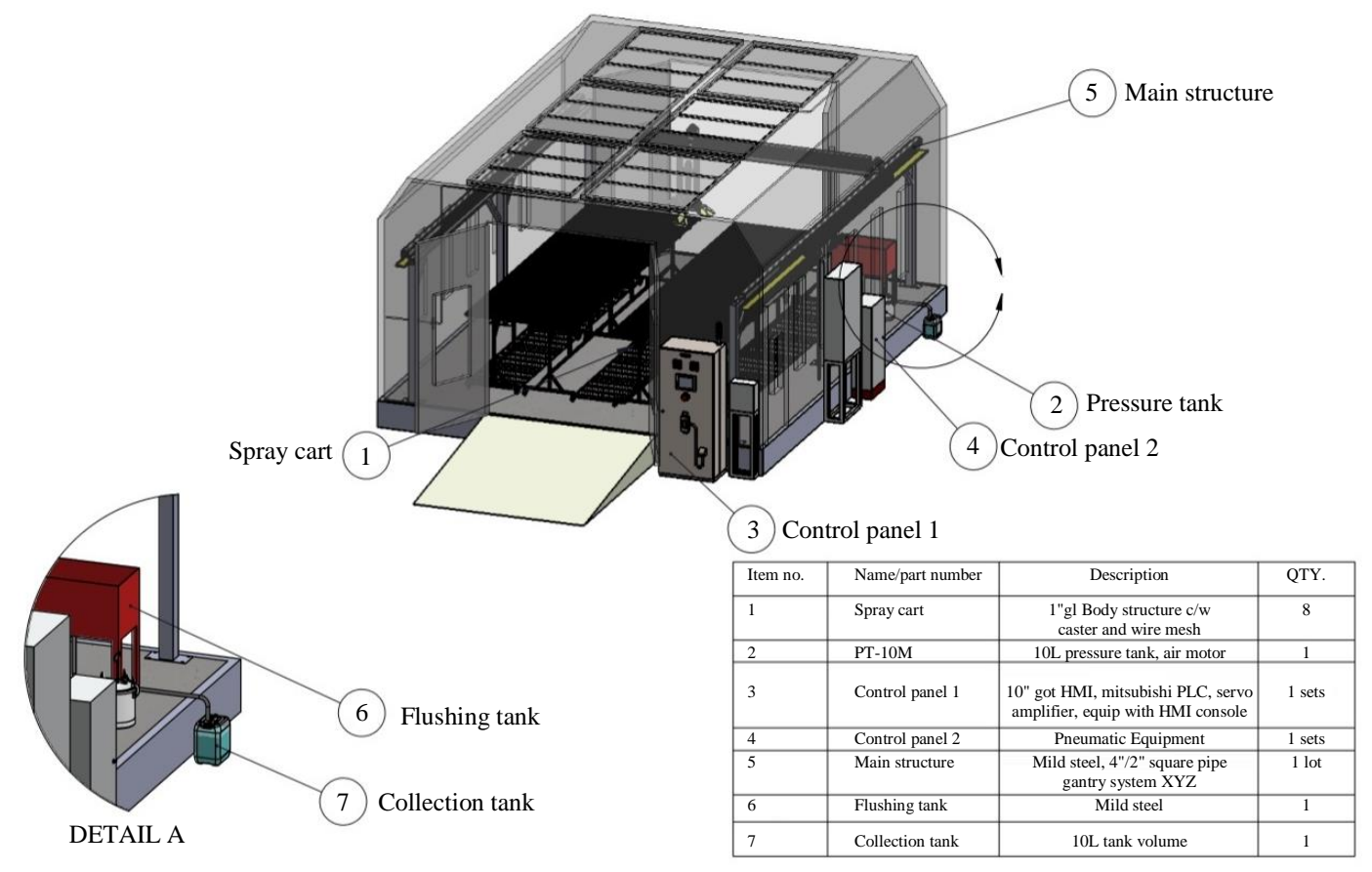

Fig. 6: Overall paint booth and asps drawing
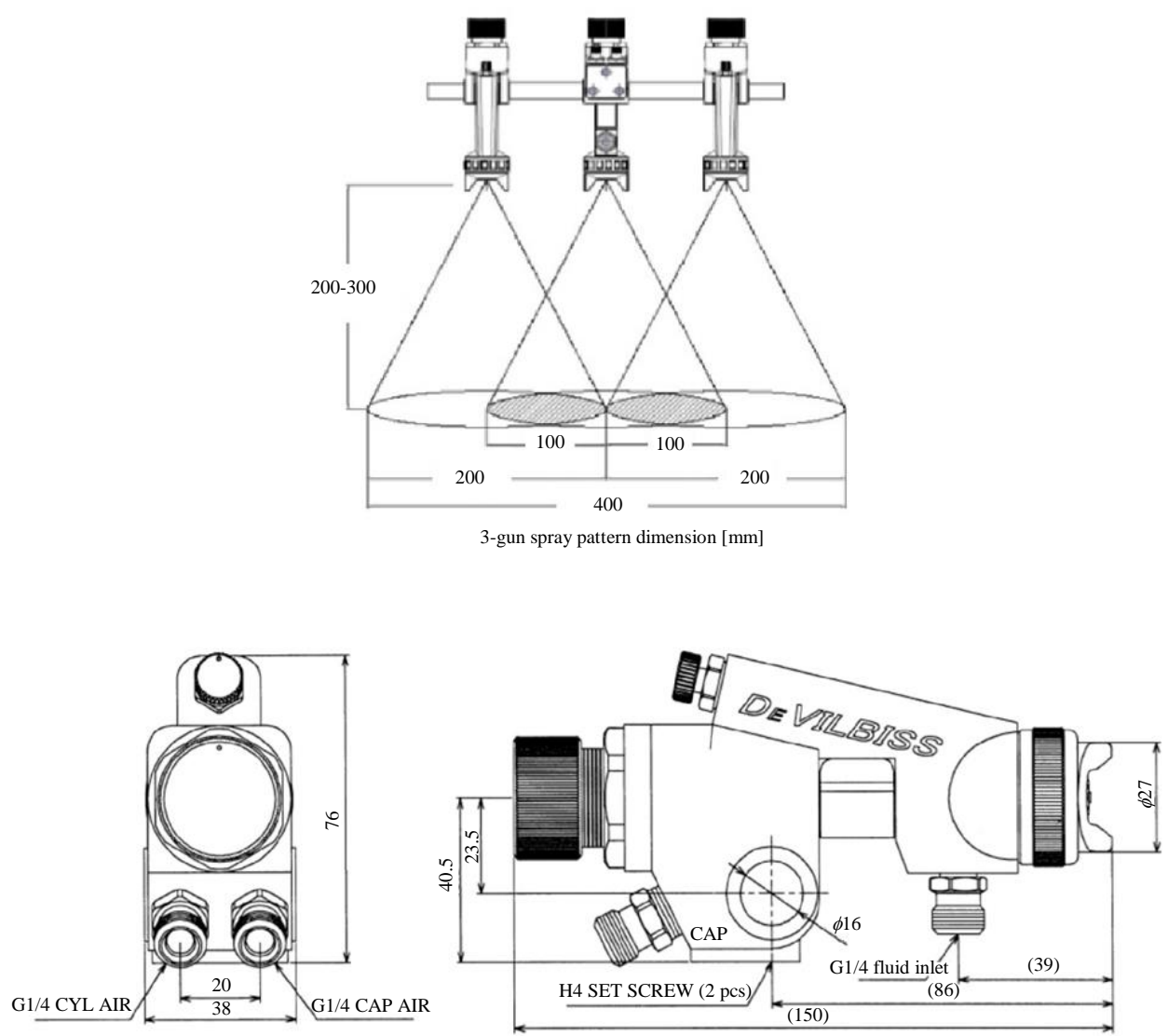

Fig. 7: Spray pattern and DA-300 type DeVilbiss (Spray and Range, n.d.) spray gun dimensions 
Figure 8 shows the process flow for the proposed ASPS:

Step 1: The operator pushes 8 carts with workpieces into the painting booth (total time took $3 \mathrm{~min}$ )

Step 2: The operator closes the door and selects JOB TYPE at the Master Control Panel (total time taken 5 min 36 2nds) Double confirm selected JOB TYPE with a height sensor. If OK, the autocoating system will start (tower light turns "GREEN." If completed, tower light turns "YELLOW")
Step 3: Flash-off period for these 8 carts (total time taken $15 \mathrm{~min}$ ). On completion, tower light turns "BLUE

Step 4: After the flash-off period completes for all 8 carts, the operator pushes all carts into Drying Booth for the next process. The operator pushes the COMPLETE button and the tower light turns "RED" (total time taken $3 \mathrm{~min}$ )

Process cycle time: Time is taken to complete the painting process for all 8 carts, including handling time: 26 min 36 2nds.

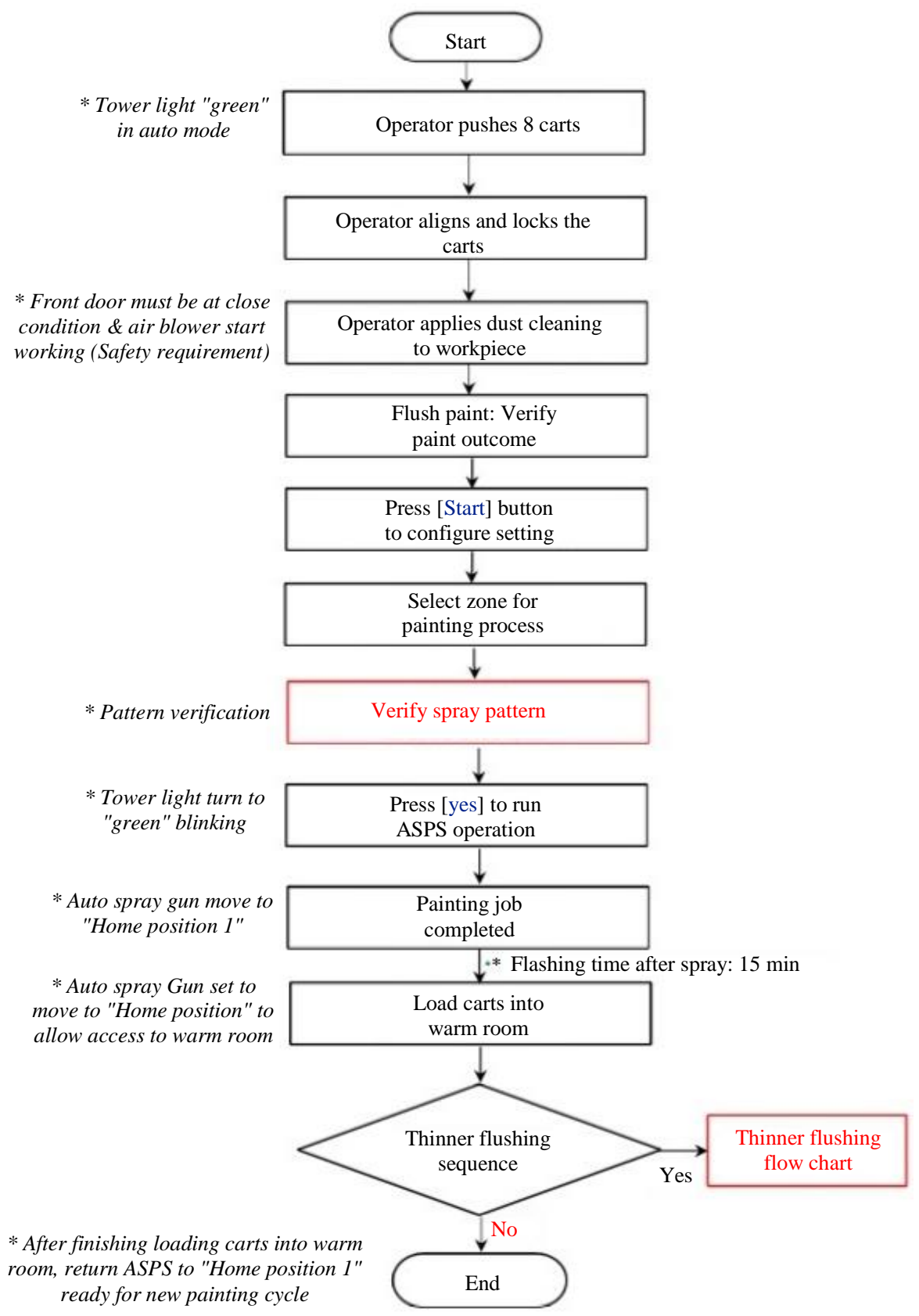

Fig. 8: Flow chart for proposed 


\section{Experimental Setup}

\section{Position Setting for Spray Gun}

In this development, we used three spray guns concept. We design the spray gun positioning which can overlap the spray pattern on each other to perform a better spray quality and maintain the thickness specification. The spray gun position design is shown in Fig. 9.

The oval pattern varies with a spray distance of 200 $\mathrm{mm}$ each. The guns are held by steel rods and positioned at a $45^{\circ}$ angle as the initial setting at the development stage, shown as a side view and can be manually adjusted based on the pattern test requirement. This testing is repeated with angle repositioning of the spray gun decreasing by $5^{\circ}$ each time until the pattern requirement as shown in Fig. 10 is achieved.

\section{Spray Pattern Test}

The guns are designed to be in such a position that when the paint is sprayed from the designated height with the correct valve opening (gun knob setting), the desired spray patterns from each gun do not overlap each other, as shown in Fig. 10. The photo shows the actual test pattern, in Fig. 10, with a width of $200 \mathrm{~mm}$ and a length of $400 \mathrm{~mm}$ that should be retained for all spray patterns. After the measurement and several tests, we found that the pattern and best angle setting is $90^{\circ}$ for the two spray guns at the outside edges (left and right gun) and the middle gun setting is $10^{\circ}$, as shown in Fig. 11 . We use the spray gun settings for further experiments with other parameters and thickness requirements, retaining this angle, as Fig. 11.

\section{Paint Material and Mixing Liquid}

Two paint materials are used in this spray-painting process from DeSoto ${ }^{\circledR}$ PPG Aerospace (n.d.) and Curing Solution and DeSoto ${ }^{\circledR} 528 \times 310$ Conductive Coating Base Component mixture. Curing solution and Base Component must be mixed in a ratio of 1:1 (Fig. 12)

\section{Calculations}

Painting area with existing carts $(4$ carts $)=6.6 \mathrm{~m}^{2}$ Cycle time to complete painting of 4 carts $=2,100 \mathrm{~s}$ Painting area with new carts $(8$ carts $)=15.55 \mathrm{~m}^{2}$ Cycle time to complete painting of 8 carts $=1,596 \mathrm{~s}$ Painting area $1 \mathrm{~m}^{2}$ with $67.8 \%$ increase in productivity

\section{Complete System Flow Chart}

The complete ASPS with automatic air flushing process flow control and thinner flushing when the new paint changing process applied is shown in Fig. 13. We use the Mitsubishi Q-Series-PLC to integrate the automatic spray gun speed, the complete system flow control, the complex algorithm and intelligent motion sequence and the process control. The Mitsubishi Q series also includes a comprehensive range of $\mathrm{I} / \mathrm{O}$ and having the full intelligent function modules to fulfill the requirements and system algorithm that we design for this ASPS application. The complete process of the proposed ASPS is easy to maintain, reduces the processing time for paint set and reduces the handling time for changing to new paint. We demonstrated that $1 \mathrm{~m}^{2}$ painting area can be completed within $102.6 \mathrm{~s}$ with this system, proving that the painting area can increase by $57.6 \%$.

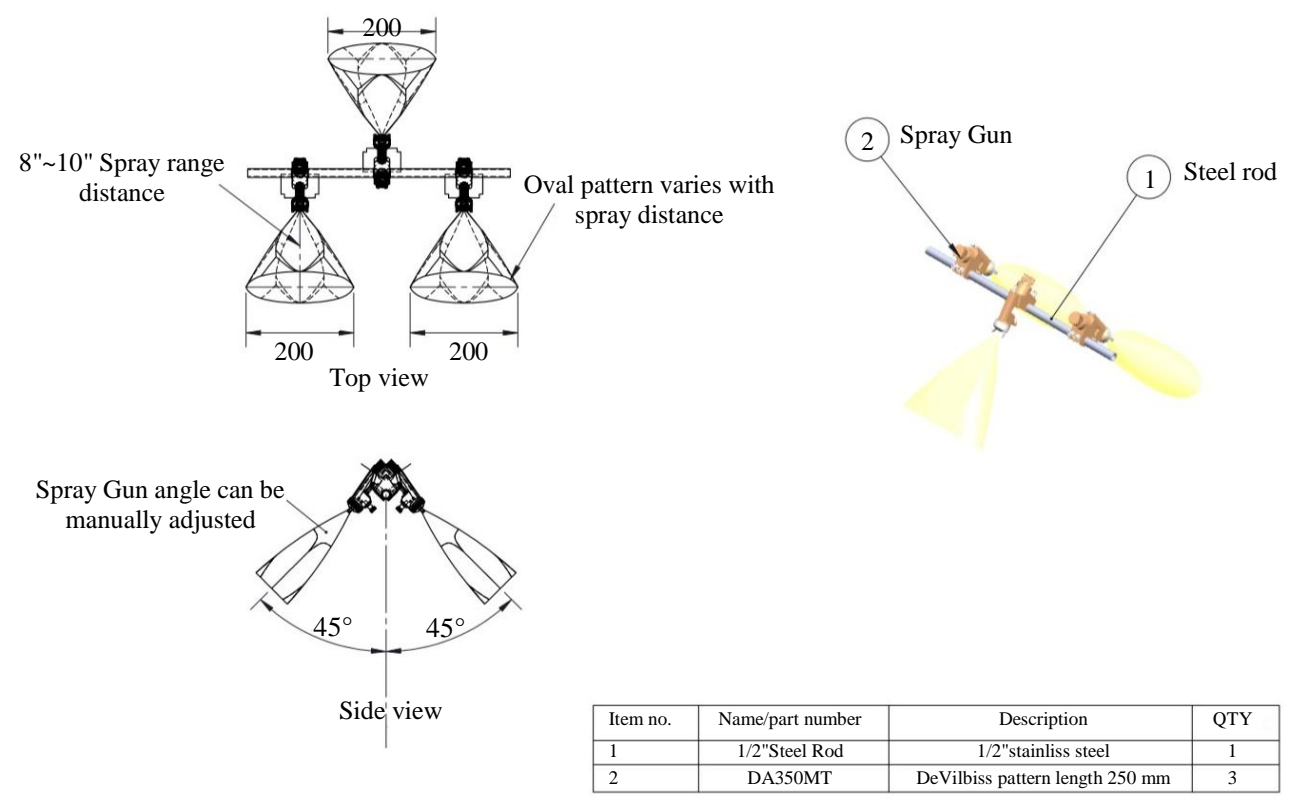

Fig. 9: ASPS design pattern and angle for spray Gum 


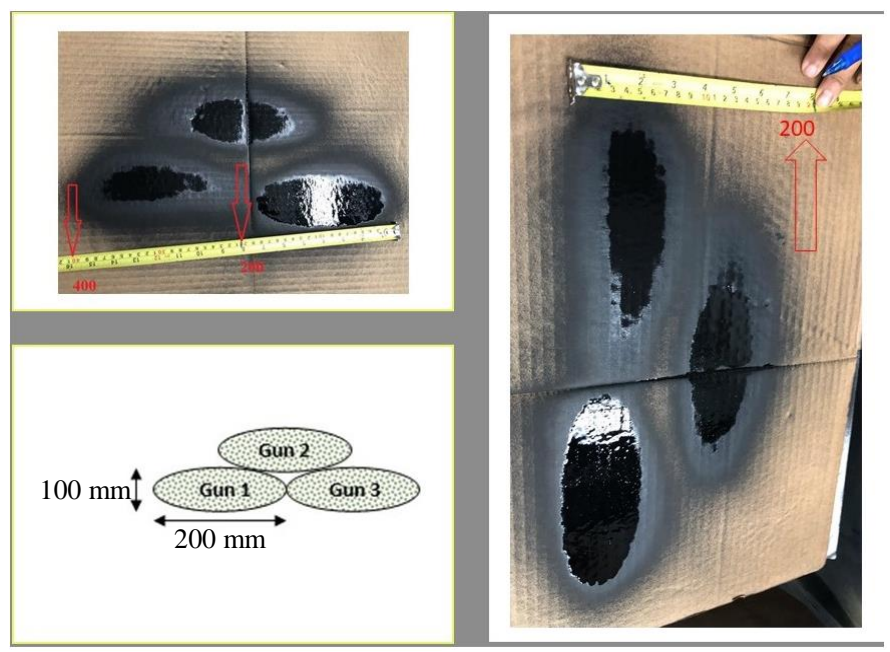

Fig. 10: Pattern test photo showing the distance kept within length $400 \mathrm{~mm}$ and width $200 \mathrm{~mm}$

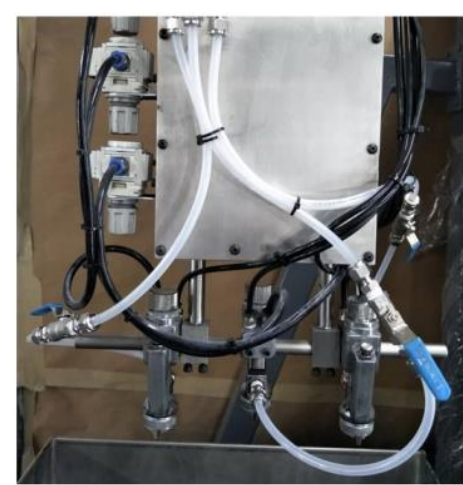

Front view

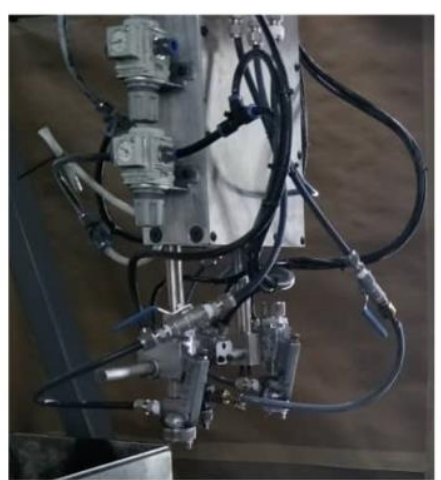

Side view

(a)

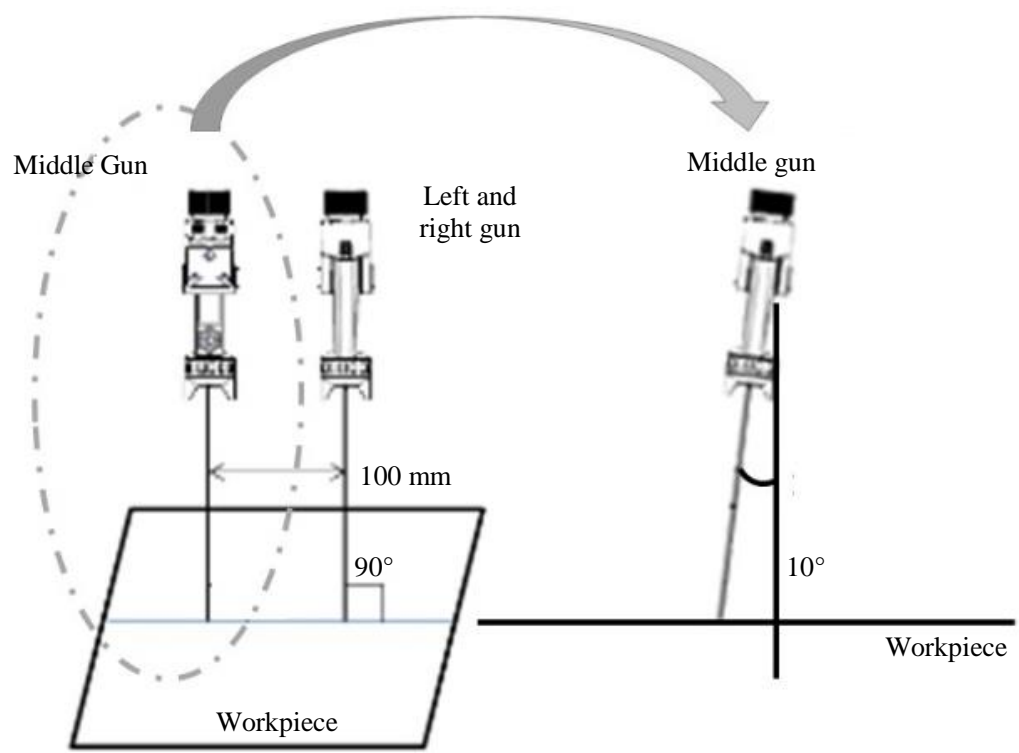

Front view

Side view

(b)

Fig. 11: Gun angle to workpiece setting after pattern test 


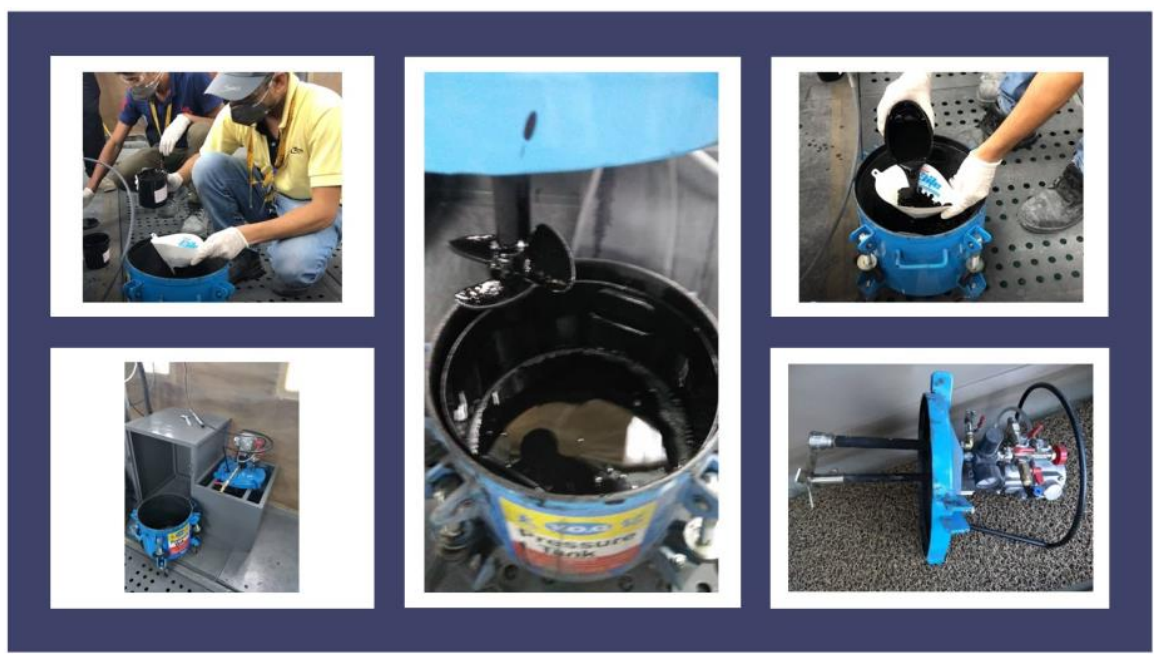

Fig. 12: ASPS Auto-mixing of paint material

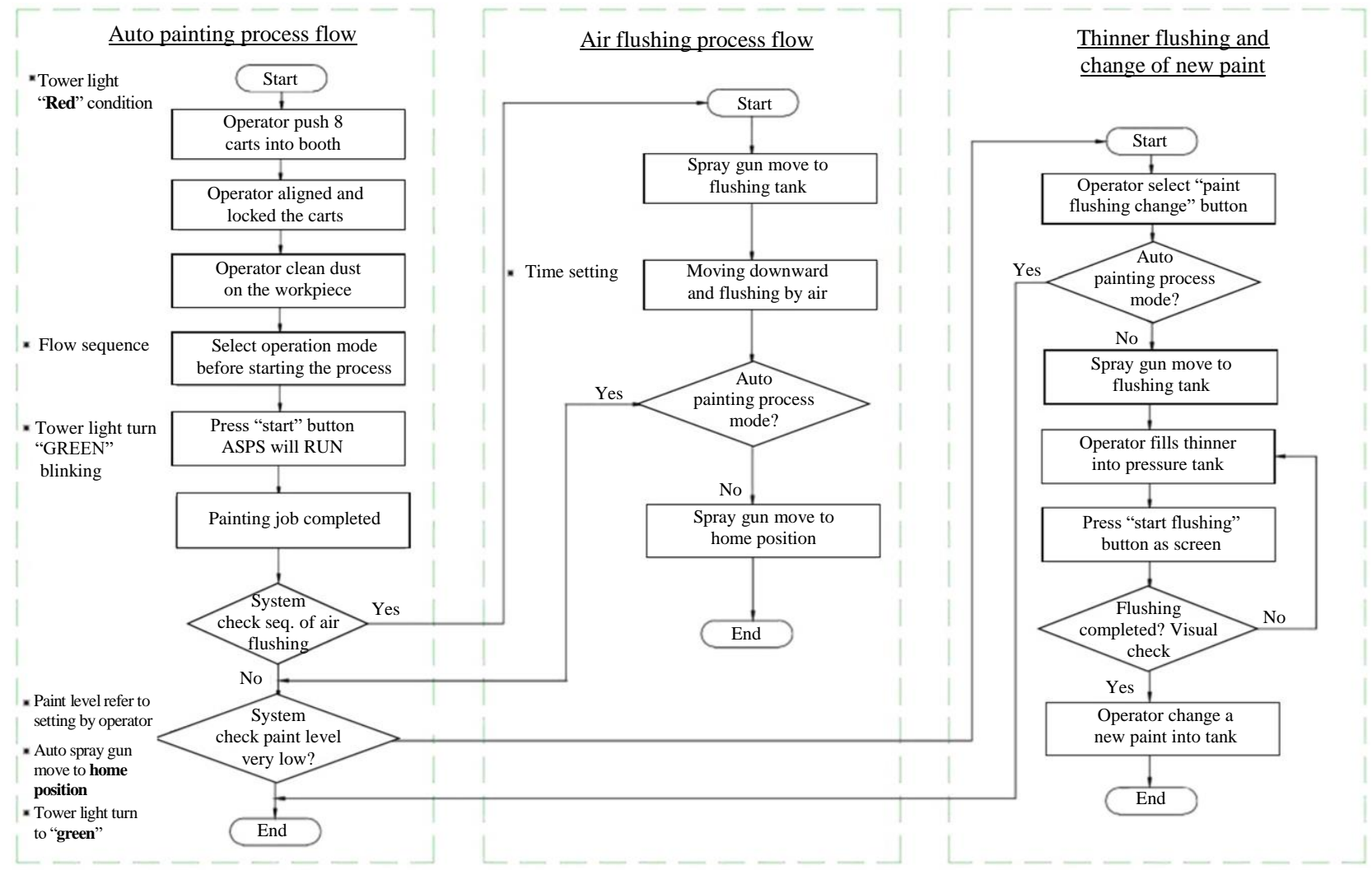

Fig. 13: Complete ASPS system flow chart with air flushing process and thinner flushing and change of new paint

\section{Discussion}

With the implementation of this automated process, it is not necessary for the operator to be inside the painting booth. This condition will be better for the safety and health of the worker. Furthermore, the requirement for space inside the booth for the operator for manual spraying process becomes unnecessary. With implementing the new cart design to new size as length, L2370 mm, width, W820 mm and high, H920 mm will increase the number of workpieces that can be located on the new cart. This new cart design could increase the number of panels, based on the increase in the painting area, by up to $57.6 \%$. 


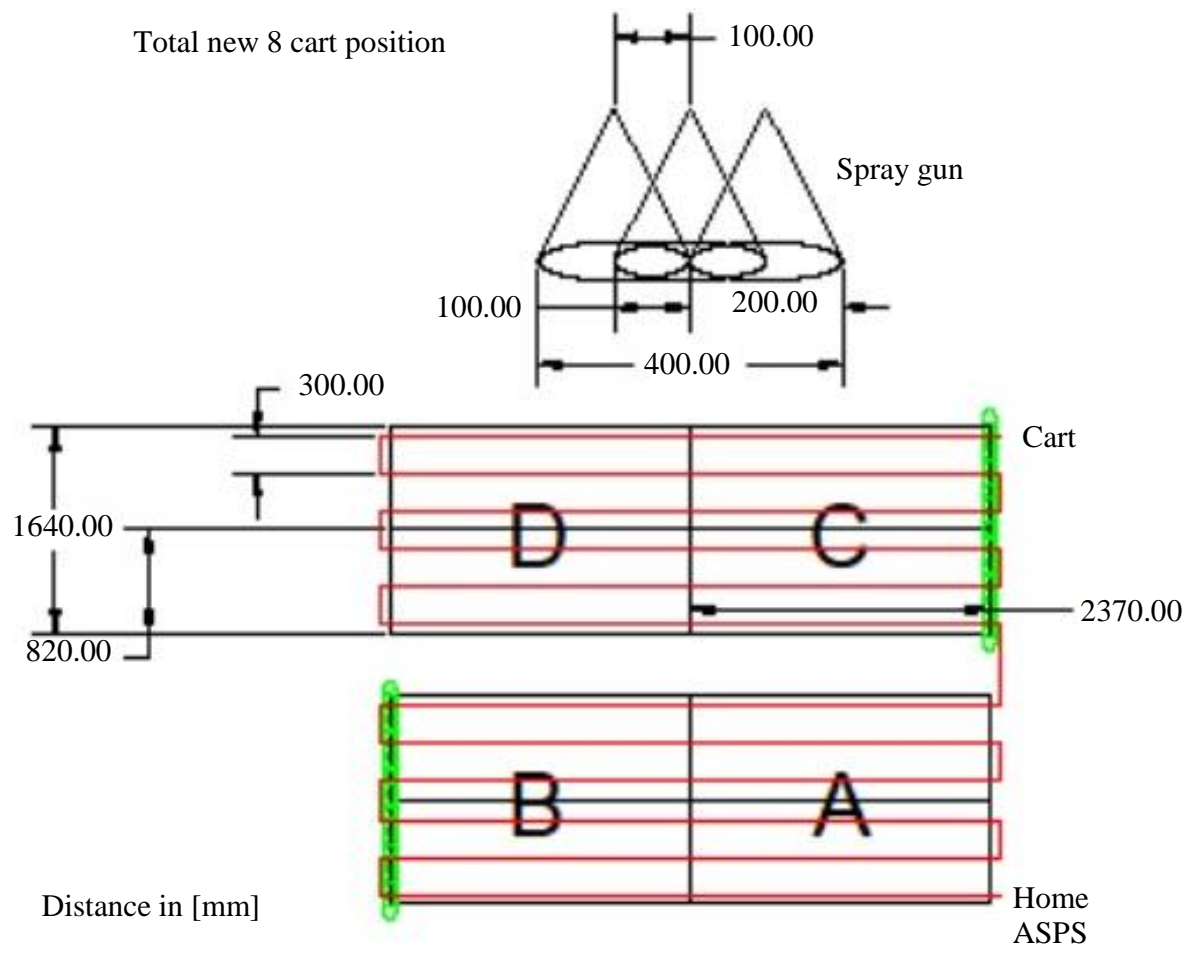

Fig. 14: Painting path with ASPS: Actual time taken 5 min. 36 2nds

Figure 14 shows the proposed ASPS cycle, actual path trajectory and travel distance during the painting process. The time taken to complete this task is 5 min 36 2nds. The total cycle time includes handling time is 26 min 36 2nds. The ASPS system showed that the robot will travel from the home position at area $\mathrm{A}$ and will paint the workpiece at area $\mathrm{B}$ before going to area $\mathrm{C}$ and finishing with area $\mathrm{D}$. The total cart area cover for this process is $15.55 \mathrm{~m}^{2}$ for eight carts. Based on the time taken for the above path, we can conclude that the painting area $1 \mathrm{~m}^{2}$ will increase productivity by $67.8 \%$ productivity from the existing manual painting system, as shown in the calculation.

\section{Results}

Several sets of studies have been performed to achieve the best spray pattern shape, optimal overlap area and most importantly even thickness. The gun knob valve opening is tested for 0.5 turns to 2.5 turns. The turn is defined, based on fully closed as 0 turns and one complete turn as 1.0 turn. Alternatively, the turn can be defined in degrees with 0 turns as $0^{\circ}$ and one complete turn as $360^{\circ}$.

To find the optimum setting for gun knob valve opening, we performed different combinations of gun knob valve opening and nozzle to the workpiece with the same fluid pressure setting at 0.8 bar, atomizing air pressure at 2.5 bar and servomotor speed at $0.4 \mathrm{~m} / \mathrm{s}$.
Figure 15 shows samples of spray coupon thickness measured and marking process. All thicknesses were measured by an Elcometer (Honda and Matsui, 1991) and recorded. The non-destructive coating thickness measurements can be taken on either magnetic steel surfaces or non-magnetic metal surfaces such as stainless steel or aluminum. Digital coating thickness gauges are ideal for measuring the coating thickness on metallic substrates. Electromagnetic induction is used for nonmagnetic coatings on ferrous substrates such as steel, while the eddy current principle is used for nonconductive coatings on non-ferrous metal substrates. A coating thickness gauge (also referred to as a paint meter) is used to measure the dry film thickness.

We setup the experiment to find the optimum height $\mathrm{H}$ for our ASPS. The experimental conditions are shown in Fig. 16. We set five different coupon samples on a wooden board and the ASPS sprayed in one direction as shown in the picture. We set al 1 coupons in the range of the pattern width per stroke $400 \mathrm{~mm}$ to achieve overlapping spray from Gun 1 with Gun 2 and Gun 2 with Gun 3 from a single spray. With the same experimental setup, we measured the parameter settings for our ASPS. The first experiment was to find the best parameter settings for the spray gun knob valve opening. In this case we setup different combinations of atomizing air pressure and ASPS servomotor speed. The results are summarized in Table 1. After several tests, we decided that the best setting for the spray gun knob turn was 0.5 
[turn]. Figure 17 shows the actual photo for the coupons before and after spray from a top view and side view.

The second parameters to be decided were atomizing pressure and servomotor speed. In this case, we performed several experiments to find the average thickness within the specification for different combinations of atomizing air pressure and ASPS servomotor speed value. The results listed in Table 2 give the optimum setting for ASPS with an atomizing air pressure of 2.5 bar from the spray gun and a servomotor speed of $0.4 \mathrm{~m} / \mathrm{s}$. We used all these parameter settings to study the range of height required to obtain the average thickness within the specification given.

The experimental results using the above parameter settings in Fig. 18 show the thickness versus nozzle to workpiece height. In this study, the coating thickness specification given was $0.4 \sim 0.8$ mils $(10 \sim 20 \mathrm{um})$. From our observation, the experiment result shown that the best thickness can be obtained with a nozzle distance from workpiece height at 10 inches. The results show that the optimum height setting for ASPS is between 8 and 10 inches to obtain the thickness within the specification and standard.
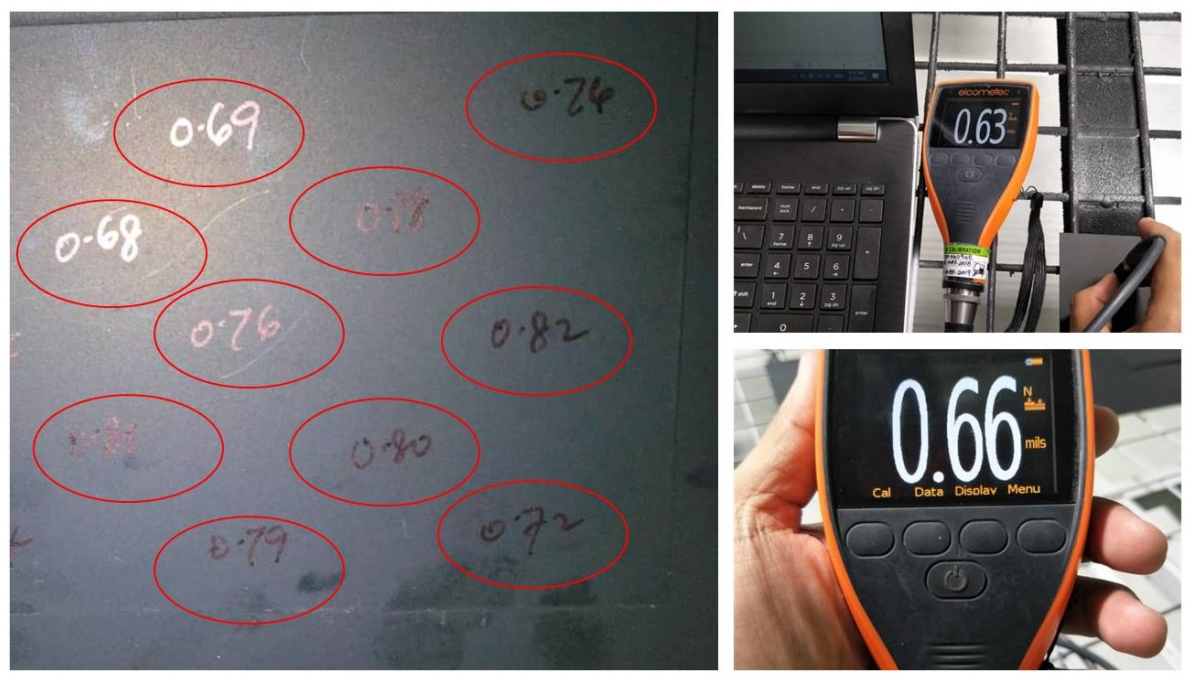

Fig. 15: Sample of coupon and data were taken by elcometer
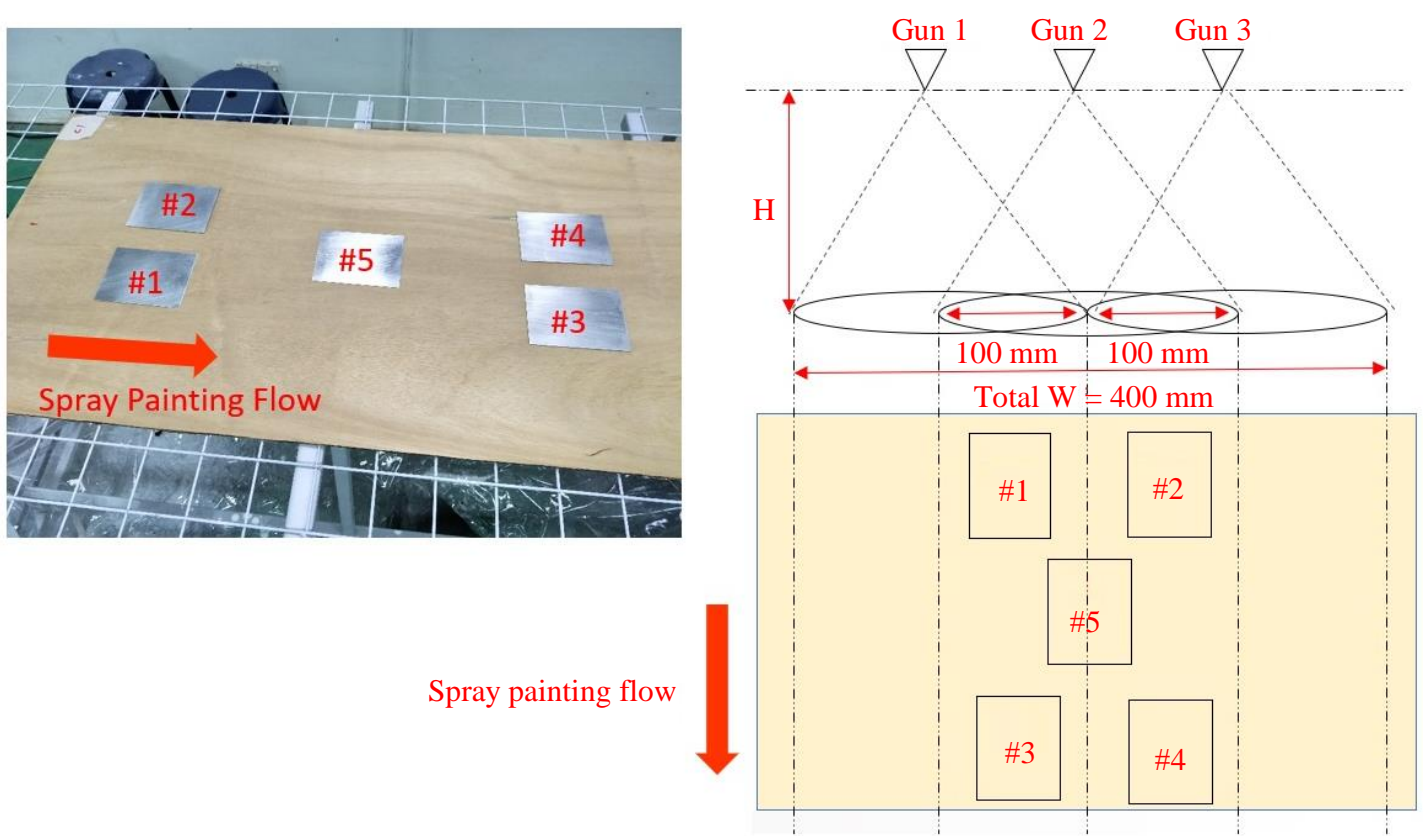

Fig. 16: Experimental setup-coupon setting condition 


\section{Sample of spray painting test}

Condition-4 (Actual panel with different level and view)
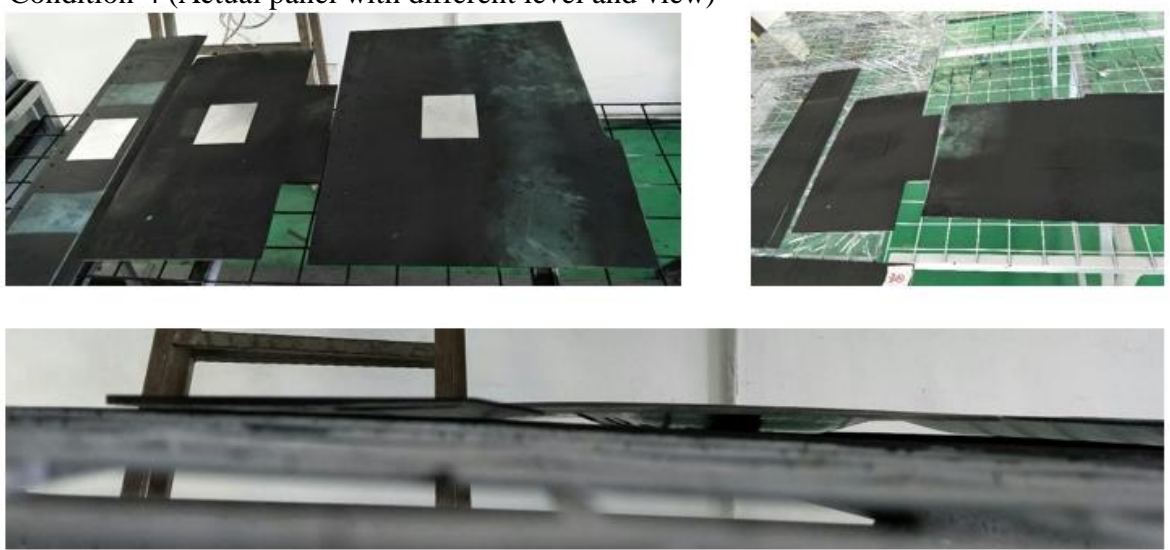

Side view of 3 actual panel with different height

Fig. 17: Photos of actual workpiece and coupon at different levels and views

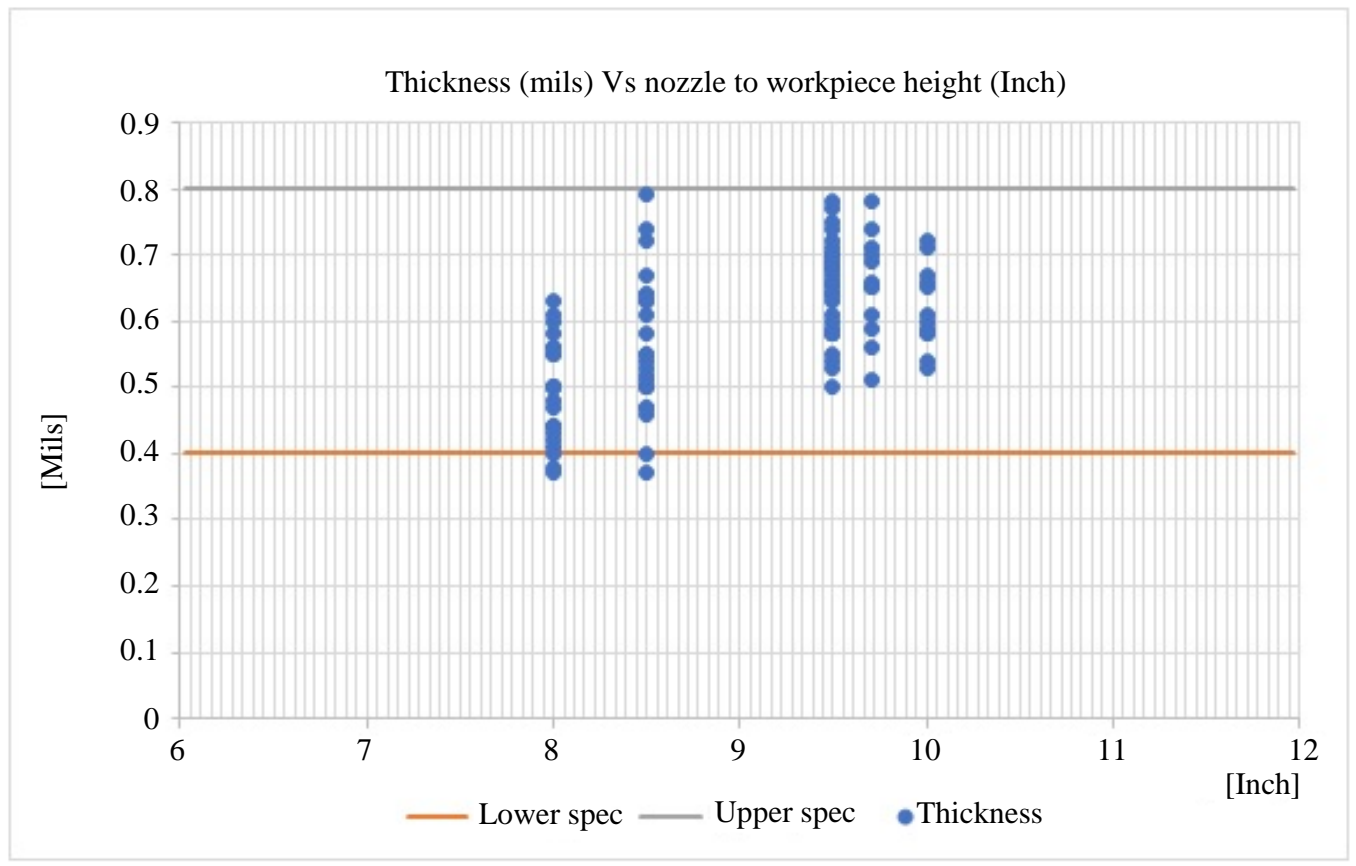

Fig. 18: The experimenstal result for thickness vs nozzle to the workpiece height

Table 1: Basic condition parameters requirement

\begin{tabular}{lcc}
\hline Fluid valve opening (Turn) & Nozzle to workpiece (Inch) & Thickness Result (mils) \\
\hline 2.0 & 8.0 & 0.9 \\
1.5 & 8.0 & 0.9 \\
0.5 & 8.0 & 0.8 \\
2.0 & 9.0 & 1.0 \\
1.5 & 9.0 & 0.9 \\
0.5 & 9.0 & 0.4 \\
2.0 & 10.0 & 1.6 \\
1.5 & 10.0 & 1.5 \\
0.5 & 10.0 & 0.4 \\
\hline
\end{tabular}


Table 2: Optimum setup atomizing air pressure versus servomotor speed

\begin{tabular}{lllllll} 
Condition & $\begin{array}{l}\text { Fluid pressure } \\
\text { bar (psi) }\end{array}$ & $\begin{array}{l}\text { Fluid } \\
\text { knob (turn) }\end{array}$ & $\begin{array}{l}\text { Atomizing air } \\
\text { pressure bar (psi) }\end{array}$ & $\begin{array}{l}\text { Servo motor } \\
\text { speed (m/s) }\end{array}$ & $\begin{array}{l}\text { Total pattern width } \\
\text { per stroke (mm) }\end{array}$ & $\begin{array}{l}\text { Thickness } \\
\text { result (mils) }\end{array}$ \\
\hline MAX & $0.8(11.6)$ & 0.5 & $3.0(43.5)$ & 0.2 & 400 & 0.74 \\
OPTI MUM & $0.8(11.6)$ & 0.5 & $2.5(36.3)$ & 0.4 & 400 & 0.65 \\
MIN & $0.8(11.6)$ & 0.5 & $2.0(29.0)$ & 0.6 & 400 & 0.40 \\
\hline
\end{tabular}

\section{Conclusion}

Dry film thickness is probably the most critical measurement in the coatings industry because of its impact on the coating process, quality and cost. This study stated the overall process of parameter setting for an automated spray-painting gantry-robot system using a 3 -gun atomization spray and using those settings to achieve the best height from a nozzle to a workpiece setting with an optimum overlapped area between the three guns to obtain the target thickness.

The outcome demonstrated that the 3-gun atomization spray method with high capacity airflow and outstanding atomization characteristics system can achieve an even thickness of overlapping spray pattern dispersed from three separate guns, minimize the paint consumption and control the dry film thickness within the given specification and standard. The optimization was performed when controlling the spraying path and control the material consumption with the 3-gun spray method to achieve the optimum setting for a spray nozzle to workpiece height and obtain the target thickness. The results showed that, by replacing the manual process, the painting process speed can increase by up to $30 \%-40 \%$, eliminate long setup times before painting and increase painting cart capacity inside the painting booth. An industry-standard assumption is that a paint saving of $15 \%$ to $30 \%$ is achieved when painting operators are replaced by ASPS. Savings achieved through film thickness tolerance control and trigger accuracy are directly related to many other savings. They can reduce stack VOC at the exhaust system; reduce rework jobs, thus increasing customer satisfaction; reduce overspray, thus reducing filter and chemical usage; and reduce reliance on expert painters, thus reducing human resources cost for hiring and training. The development of this system can achieve the thickness specification, increase productivity and develop a safe working environment in order to optimize a safer, more effective and ergonomic workplace and process.

In future work we need to use ASPS parameter settings, pattern test results, all height data to develop an intelligent autonomous height control system for ASPS which have the flexibility to change, expansion and adaption to different workpiece sizes, type and paint thickness. This work will concern deeper analysis of particular mechanisms for the ASPS to suit various types of a workpiece with an autonomous height control system. Many different adaptations, tests and experiments can be potentially developed in the future.

\section{Acknowledgment}

This project is a Professional Engineer assessment for the corresponding author under the Institute of Engineering Malaysia ("IEM," n.d.). Special thanks to all members of ACM (ACM Malaysia, 2002), Ir. Haji Abdul Kadir and Ir. Hj. Shamil $\mathrm{Hj}$. Abu Hassan ("Professional Engineer Interview: An expert guide to a successful Application by Ir. Hj. Shamil Hj. Abu Hassan - DRB-HICOM University of Automotive Malaysia," n.d.) for their support and Universiti Malaysia Perlis ("UniMAP |Universiti Malaysia Perlis - HOME," n.d.) for providing the research expertise for this project.

\section{Funding Information}

This research project was funded by ACM (ACM Malaysia, 2002) under the industry research grant.

\section{Author's Contributions}

Zunaidi Ibrahim: Main contribution and corresponding author-project key person and the main contributor for the design of research plan and organize the project.

Rozman A. Rahim: Conception and designparticipated in the experimental setup, assembly and installation the project. Provide expertise from NS Aries (NS Aries Sdn Bhd, Malaysia).

Shahrizal Ariffadillah: Installation and experimentparticipated in preparing of work place of installation of the project and his contribution on engineering work and production site work.

Zuradzman Mohd Razlan: Drafting and reviewingcontribute to the manuscript writing mainly in preparing the literature review of the manuscript.

Shahriman Abu Bakar: Drafting and reviewingcontributed to the manuscript writing and technical contents review.

Wan Khairunizam: Acquisition of data-coordinated the data analysis for this project.

Rudzuan M. Nor: Data analysis and interpretationpreparing data collection and analyzed for this project.

\section{Ethics}

This paper was continuity but not similar to our previous paper titled "Development of Automated Spray- Painting System for Anti-Static Coating Process", (Rudzuan et al., 
2019) and was published in Conference Proceeding under IOP Conference Series Science Engineering.

\section{References}

ACM Malaysia, 2002. Products and Services | ACM. Aerospace Coatings, (n.d.). Aviox finish 77702 AkzoNobel aerospace coatings - AkzoNobel. https://aerospace.akzonobel.com/product/avioxfinish -77702application-by-ir-hj-shamil-hj-abuhassan/

United States Department of Transportation and Federal Aviation Administration, 2012. Aircraft painting and finishing. Aviation maintenance technician Handbook-Airframe.

Chen, W. and D. Zhao, 2013. Path planning for spray painting robot of workpiece surfaces. Math. Problems Eng.

Chidhambara, K.V., B. Latha Shankar and Vijaykumar, 2018. Optimization of robotic spray painting process parameters using taguchi method. IOP Conf. Series: Mater. Sci. Eng.

Coating.co.uk, (n.d.). Aerospace coatings-aircraft and amp; aviation paint | Coating.co.uk. https://www.coating.co.uk/aerospace-coating/

Conner, D.C., A. Greenfield, P.N. Atkar, A.A. Rizzi and H. Choset, 2005. Paint deposition modeling for trajectory planning on automotive surfaces. IEEE Tran. Automat. Sci. Eng., 2: 381-391.

DOI: $10.1109 /$ TASE.2005.851631

DeSoto® PPG Aerospace, (n.d.). Aerospace coatings for commercial, general aviation, military aircraft by PPG-PPG industries-aerospace. http://www.ppgaerospace.com/Products/CoatingsRemovers-Cleaners.aspx

Engineering, I., 2015. Six DOF spray painting robot analysis.

From, P.J., J. Gunnar and J.T. Gravdahl, 2011. Optimal paint gun orientation in spray paint applicationsexperimental results. IEEE Tran. Automat. Sci. Eng., 8: 438-442.

DOI: 10.1109/TASE.2010.2089450

Gantry Systems: Working Outside the Envelope-Macron Dynamics., (n.d.). https://www.macrondynamics.com/jobstories/gantry -systems-overview

Halin, H., W. Khairunizam, K. Ikram, H. Haris and S.A. Bakar et al., 2018. Investigation of Steering Wheel Control of an Electric Buggy Car for Designing Fuzzy Controller. In: Intelligent Manufacturing and Mechatronics Lecture Notes in Mechanical Engineering, Hassan, M. (Ed.), Springer, Singapore, ISBN-13: 978-981-10-8787-5. pp: 459-468.

Hariraj, V., W.K. Vikneswaran and Z. Ibrahim, 2018. Fuzzy multi-layer SVM classification. Int. J. Mech. Eng. Technol., 9: 1281-1299.
Hexcel HexAMTM, 2019. Hexcel HexAMTM additive manufacturing approved by Boeing for commercial aircraft platforms.

Honda, T. and K. Matsui, 1991. Coating thickness gauge. Infrared Technology XVII.

Ibrahim, Z., R. Nagarajan, M. Rizon, D. Hazry and D. Ruslizam et al., 2008. Electromyography signal based for intelligent prosthesis design. Proceedings of the 4th Kuala Lumpur International Conference on Biomedical Engineering, (CBE' 08), Springer, Berlin, pp: 187-190.

IEM, (n.d.). https://www.myiem.org.my/

Khalifa, A., K. Sundaraj, Z. Ibrahim and V. Retnasamy, 2007. Complex background subtraction for biometric identification. Proceedings of the International Conference on Intelligent and Advanced Systems, Nov. 25-28, IEEE Xplore Press, Kuala Lumpur, Malaysia, pp: 696-701. DOI: $10.1109 /$ ICIAS.2007.4658477

Li, X., O.A. Landsnes, H. Chen, M.V. Sudarshan and T.A. Fuhlbrigge et al., 2010. Automatic Trajectory Generation for Robotic Painting Application. Proceedings of the 41st International Symposium on Robotics and 6th German Conference on Robotics, Jun. 7-9, IEEE Xplore Press, Munich, Germany, pp: 1-6.

Luangkularb, S., S. Prombanpong and V. Tangwarodomnukun, 2014. Material consumption and dry film thickness in spray coating process. Proc. CIRP, 17: 789-794.

DOI: $10.1016 /$ j.procir.2014.02.046

Madhuraghava, P., D.F. Basha and V.S. Reddy, 2018. Modelling and structural, analysis of a 6-DOF robot spray coating manipulator. Int. J. Eng. Sci., 7: 48-56. DOI: $10.9790 / 1813-0701014856$

Manual, I., 2012. Servo motor. Specialty Fabrics Rev.

Meng, F., 2008. Trajectory and spray control planning on unknown 3D surfaces for industrial spray painting robot.

Mike, R., 2012. Coatings for composites-Aerospace manufacturing magazine.

Mustafa, W.A., H. Aziz, W. Khairunizam, Z. Ibrahim and A.B. Shahriman et al., 2018. Review of different binarization approaches on degraded document images. Proceedings of the International Conference on Computational Approach in Smart Systems Design and Applications, Aug. 15-17, IEEE Xplore Press, Kuching, Malaysia. DOI: $10.1109 /$ ICASSDA.2018.8477621

NS ARIES SDN BHD | Malaysia Robotics and Engineering Solutions., (n.d.). http://www.aries.com.my/v4/index.php

Pressure, M.W. and M.W. Temperature, (n.d.). Rolypoly. 1-2. Professional Engineer Interview: An expert guide to a successful Application by Ir. $\mathrm{Hj}$. Shamil Hj. Abu Hassan - DRB-HICOM University of Automotive. 
Rebecca Horner., (n.d.). Aero 12 - improved paint durability.

http://www.boeing.com/commercial/aeromagazine/a ero_12/paint_story.html

Rudzuan, M.N., W. Khairunizam, I. Zunaidi, Z.M. Razlan and A.B. Shahriman et al., 2019. development of automated spray-painting system for anti-static coating process. IOP Conf. Series: Mat. Sci. Eng.

Sheng, W., H. Chen, N. Xi and Y. Chen, 2005. Tool path planning for compound surfaces in spray forming processes. IEEE Tran. Automat. Sci. Eng., 2: 240-249. DOI: 10.1109/TASE.2005.847739

Somboonwiwat, N. and S. Prombanpong, 2017. An optimization of spray coating process to minimize coating material consumption. Proceedings of the 31st European Conference on Modelling and Simulation, (CMS’ 17), pp: 247-251.

Spray, C. and G. Range, (n.d.). DeVilbiss advance. DeVilbiss.
Taejung, K. and S.E. Sarma, 2003. Optimal sweeping paths on a 2-manifold: a new class of optimization problems defined by path structures. IEEE Tran. Robot. Automat., 19: 613-636.

DOI: $10.1109 /$ tra.2003.814497

Tang, Y. and W. Chen, 2015. Surface modeling of workpiece and tool trajectory planning for spray painting robot. PLOS One, 10: 1-9.

DOI: 10.1371/journal.pone.0127139

Techniques, P., 2018. Aircraft paint application manual. Products Techniques, Inc.

UniMAP |Universiti Malaysia Perlis - HOME. (n.d.). https://www.unimap.edu.my/index.php/en/

Zunaidi, I., N. Kato, Y. Nomura and H. Matsui, 2006. Path planning based on geographical features information for an autonomous mobile robot. Artificial Life Robot., 10: 149-156.

DOI: $10.1007 / \mathrm{S} 10015-005-0371-7$ 